\title{
Bibliografia \\ comentada das \\ obras sobre \\ Walter Benjamin \\ no Brasil
}

Literatura secundária: livros, ensaios em revistas e jornais.

ASCHER, Nelson. “Autor Vivia nos Limites", in Folha de S. Paulo, "Mais!”, 127/92, p. 5. Nota sobre a recepçáo de W.B. dentro de várias tendências do pensamento: o marxismo, a cultura judaica centro-européia e a crítica literária da primeira metade do século XX. W. B. é associado a autores sobre os quais escreveu: Kafka, Brecht e Baudelaire.

AUGUSTO, Sérgio. "Intelectual Também Vive o Melodrama", in Folha de S. Paulo, 7/ 10/1989, p. G-6 Resenha sobre a publicaçāo do livro Diário de Moscou de W. B., o qual esteve em Moscou entre dezembro de 1926 c final de janeiro de 1927.

. "Filósofo das Iluminaçōes", in Folha de S. Paulo, "Mais!", 12/7/92, p. 4. Artigo sobre a comemoraçăo do centenário do nascimento de W. B., um intelectual que conseguiu unir em si mesmo todas as contradiçōes de sua época. Trechos biográficos.

BARROS E SILVA, Fernando de. "Encontro Faz 7 Perguntas a W. B.", in Folha de S. Paulo, 25/9/1990, p. F-1. Artigo sobre o simpósio brasileiro-alemão no Instituto Goethe em São Paulo, 1990; dados biográficos e aspectos da obra; lista das obras disponiveis no Brasil; o programa do simpósio e os participantes.

BOLLE, Willi. "O Crítico Sem Nenhum Caráter", in OEstado de S.Paulo, "Suplemento Cultural”, 19/6/1977, pp. 10 e se Friedrich Schlegel, pioneiro da Modernidade, discutido por W.B., autor de uma tese de doutorado sobre $O$ Conceito de Critica de Arte no Romantismo Alemāo (1919).

.W. B. e o Teatro", in Folha de S. Paulo, "Folhetim", 29/5/1983, pp. 3-5 Análise de Origem do Drama Barroco Alemäo (1916-28), de W. B., no contexto de outros escritos seus sobre o teatro.

- "Cultura, Patrimônio e Preservaçāo", in Produzindo o Passado. Estratégias de Construçāodo Patrimônio Cultural (ed. A. A. Arantes). São Paulo, Brasiliense, 1984, pp. 11-23. Definiçäo desses três conceitos à luz do texto Infância Berlinense por Volta de 1900 (1930), de W.B.
GUNTER KARL

PRESSLER ẻ

doutorando da Universidade de Sáo

Paulo. onde elabora um trabalho sobre a recepção da obra de Water Benjamin no Brasil.

Gostana de saiserey are co a sos pubicados na Revista USP $n^{*} 15$, dossid Warer Benjamin, * na rovista O que nos taz ponsar. Cadernos do Departamento de Filosofla da PUC-RU, $n^{\circ} 6$, nso foram incluidos nesta biblografia. 
"W.B. e a Cultura da Criança", in W.B., Reflexōes: a Criança, o Brinquedo, e a Educaçāo. São Paulo, Summus, 1984, pp. 13-6. Observaçōes sobre a relaçāo entre os preceitos pedagógicos do adulto e a cultura da criança, com seus valores autônomos.

. Tableaux Berlinois. W.B. e a Cultura da República de Weimar. Tese de livredocência mimeografada. São Paulo, FFLCH-USP, 1984. Análise da obra de W.B. segundo três recortes: a ciência acadêmica (questōes de método), a crítica jornalistica (a militância nos anos de crise da República de Weimar) e o projeto do escritor (fisionomia da metrópole moderna).

. "Fisionomia da Metrópole Moderna. Os 'Retratos' Benjaminianos de Cidades", in Folha de S. Paulo, "Folhetim", 9/12/1984, pp. 3-5. Resumo da tese de livredocência, centrado sobre o projeto benjaminiano de representaçáo da metrópole: a cidade como texto; a cidade erotizada; cidade e memória; a polis mítica.

"W.B.: Fisionomista da Metrópole Moderna", in Ocuium n² 1, Campinas, 1985, pp. 40-3. Semelhante ao artigo anterior, numa versão diferente.

"Caçadores do Sexto Sentido. O Novo Ensaismo Benjaminiano", in Folha de S. Paulo, "Folhetim", 1/9/1985, pp. 8-10. Resenha de novos ensaístas alemães da década de 1980, que se situam em parte dentro da tradiçāo benjaminiana.

"Apresentaçāo", in W.B., Documentos de Cultura-Documentos de Barbárie. Escritos Escolinidos (ed. Willi Bolle). São Paulo, Cultrix. 1986, pp. 9-14.

Introduçāo à antologia, realçando sua utilidade como textbook sobre questōes de literatura, cultura e política na República de Weimar.

. "Literatura e Técnica. A Modernidade Fascista", in Folha de S. Paulo, "Folhetim", 13/11/1987, pp. 6-9. Sobre Ernst Juenger e W.B. Análise do livro $O$ Operário (1932), de Juenger, que mostra a metrópole na ótica do guerreiro e antecipa algumas das observaçōes do ensaio de W.B. sobre "A Obra de Arte na Era de sua Reprodutibilidade Técnica" (1935-36).

"A Modemidade Segundo W.B.", in Revista da Universidade de Säo Paulo, n 5, 1987. pp. 46-56. Análise de "A Paris do Segundo Império em Baudelaire" (1938) enquanto representaçāo da experiência histórica do crítico W.B. (192338). Descrição do texto como "ensaio cinematográfico".

"A Modernidade como Trauerspiel. Representação da História em W.B., Origem do Drama Barroco Alemāo", in Revista de História (Nova Série), $\mathrm{n}^{2} 119,1985$ 88, pp. 43-68. Análise do livro de W.B. sobre o drama barroco (Trauerspiel). Historiografia alegórica e crítica da cultura. Histórico de uma emoçāo: melancolia. Alegoria barroca e moderna. Baudelaire, poeta alegórico. Do palco barroco à cidade surrealista.

. "Pensamento Privilegiado e Cultura de Massas. Tradição e Modemidade em W.B.", in Linha D'água, $\mathrm{n}^{2} 6,1989$, pp. 13-29. Sobre a formaçāo do crítico W.B. Crítica da universidade e do Jugendstil. Conservadorismo, marxismo e experiência do escritor autỏnomo. Resgate da tradiçāo da própria classe.

"Viagem a Moscou. O Mito da Revolução", in Revista USP, n²5, 1990, pp. 11734. A experiência soviética de W.B. em 1926-27. Divergências de visão entre seus textos publicados na época e seu diánio. Postura de W.B. diante dos escritores proletários-revolucionários na Alemanha.

- Fisionomia da Metrópole Moderna Representação da História em W.B. São Paulo, Edusp, 1992. O livro, uma síntese dos estudos de Willi Bolle sobre W.B., 
éuma leitura da modemidade peloprisma da obra deste pensador. A "îsionomis" da metrópole moderna resulta da superposiçāo dos retratos benjaminianos de cidades (Berlim, Paris, Moscou) com o lugar de sua recepçāoe "revelação": São Paulo. Descrição da construçāo benjaminiana do olhar sobre a cidade, dos conceitos de critica e historiografia. Imagem da época entre as duas guerras mundiais, mostrando o critico militante e as forças históricas: modernidade e tradição, comunismo e fascismo, midia e massas. Um balanço da modernidade, resgatando fenômenos culturais de longa duração: escrita, memória, imaginário social.

BORLETTI, Silvia Helena Simōes. “Memória e Temporalidade: Diálogo entre W.B. e Henri Bergson", in Margem, Faculdade de Ciências Sociais-Pontifícia Universidade Católica de São Paulo, 1992, pp. 79-90. Sobre o conceito da "experiência" e o "declínio da aura"(W.B.). Trata também do conceito da "intuiçăo" e o processo: imagens, cérebro, ação e percepçāo (Bergson).

B RAGA, Regina Stela. "O Filósofo e o Poeta", in O Globo, 17/9/89. Resenha sobre o vol. III das Obras Escolinidas. Discute a ligaçâo entre W.B. e Baudelaire.

CAMPOS, Haroldo de. "Para Além do Principio da Saudade. A Teoria Benjaminiana da Tradução", in Folha de S. Paulo, "Folhetim", 9/12/1984, pp. Discute a teoria de tradução de W.B. no texto “A Tarefa do Tradutor" (1923). Compara filosofia e traduçāo na referência a Lukács. Cita os textos de W.B. sobre a teoria da linguagem e comenta a traduçāo de W.B. sobre uma poesia de Hoelderlin.

. "Octavio Paz e a Poética da Tradução", in Folha de S. Paulo, "Folhetim", 9/1/ 87, pp. 3-5. Refere-se à teoria e terminologia de W.B., discutindo a questāo da traduçāo.

CARVALHO, Gilmar de. "Benjaminianas", in W.B., Curso de Comunicação Social na Universidade Federal do Ceará, nov,/1990, 13/1. Uma poesia dedicada à W.B. (Retratos de cidades.)

CASTRO, Paulo de. "Conflitos e Enigmas de W.B.", in Folha de S. Paulo, 17//1983, p. 74. Sobre a publicação francesa das cartas de W.B. entre 1929 e 1940, as quais foram publicadas em inglês por S. Buck-Morss.

COELHO, Marcelo. "Mosaico de Textos e Aforismos de W.B.", in Folha de S. Paulo, 21/11/1987, p. A-32. Resenha sobre o volume III das Obres Escolhidas de W.B.

CORDEIRO, Zahira Souki.AAlegoria como Conceito: uma Leitura Benjaminiana do Barroco. Belo Honizonte, Universidade Federal de Minas Gerais, 1992. Dissertaçāo de Mestrado. A tese mostra o background do pensamento de W.B. Abordagem da história do conceito de "alegoria" e uma crítica da concepçāo romāntica de alegoria. Análise do conceito no drama barroco alemâo.

COSTA, Caio Túlio. "A Última Guardia de W.B.", in Folha de S. Paulo, 24/10/1987, pp. A-28/29. Sobre o livro de Lisa Fittko traduzido do alemāo para o francês. As memónias da autora narram sua ajuda aos refugiados judeu-alemōes na França, incluindo a fuga, fracasso e morte de W.B.

COUTINHO, Wilson. "Um Poeta Sob os Véus da Alegoria", in Jornal do Brasil, 2/12/ 1989, p. 8. Resenha do vol. III dolivro Charles Baudelaire - um Lírico noAuge do Capitalismo.

DIAS, Carmen. "Willi Bolle, na Trilha de W.B.", in O Povo, Fortaleza, 8/11/1990, p. B6. Entrevista com o estudioso benjaminiano, professor Willi Bolle, que trata o 
conceito de modemidade e fala sobre o suicidio nos das Passagens) (1927-40) para mostrar e explicar o método benjaminiano na busca da verdade filosófica, nos objetos e detalhes do cotidiano. Uma busca tanto na obra de juventude quanto na obra tardia de W.B.

GERZOVICH, Diego. "W.B. Analisa o Homem Moderno", in O Povo, Fortaleza, 23/ 11/1990. Análise da figura benjaminiana do fláneur, como um tipo que representa na teoria da modernidade o homem moderno e urbano.

GIORGIO, Flávio di. "Benjamin e a Militância da Memóna", in Folha de S. Paulo, 18/ 3/84, p. 7. Resenha do livro Reflexōes: a Criança, o Brinquedo, a Educaçāo, da Editora Summus.

GOLDGRUB, Franklin. "A História de uma Amizade", in O Estado de S. Paulo, 24/6/ 89, pp. 10-11. Resenha do livro de Gershom Scholem História de uma Amizade, no qual o autor fala de sua ligação com W.B.

GONÇALVES. Marco Augusto. "Benjamin, o Pensador do Mundo Fragmentado", in Folha de S. Paulo, 3/11/84. Entrevista com o tradutor e estudioso de W.B., Willi Bolle, sobre o lançamento da traduçào da obra Origem do Drama Barroco Alemāo.

GURGEL, Marcia. "W.B. Uma Semana de Esclarecimento", in O Povo, Fortaleza, 5/11/ 1990. Artigo sobre “A Semana de W.B." em Fortaleza, 1990.

HIRSCH, Alfred. "Limiar e Transiçāo. A Obra de W.B.", in Humboldt $n^{2} 62$, Inter Nationes (Bonn), 1991, pp. 62-5. O ensaio abrange dados biográficos de W.B., bem como o objetivo desse autor de delimitar e conhecer o outro lado do pensamento. A Obra das Passagens deveria ter se tornado sua obra principal, o exemplo para delimitar a fronteira da experiência e o conhecimento histórico.

JUNQUEIRA, Ivan. "Charles Baudelaire: Um Diálogo com a Modemidade", in $O$ Estado de S. Paulo, 9/12/1989, p. 10. Tradutor de Baudelaire. Ratifica a interpretação de W.B. sobre a modernidade e o papel central de Baudelaire naquela.

JUNQUEIRO, Ronald. “Olhar Iluminadosobre Tempos Sombrios", in OLiberal, Belém, 4/11/1990, p. C 1. Artigo sobre o "Simpósio de W.B." na Universidade de Belém, 1990.

KONDER, Leandro. "Os Marxistase a Arte. Breve Estudo Histórico-Critico de Algurnas Tendências da Estética Marxista". Rio de Janeiro, Civilizaçāo Brasileira, 1967, pp. 121-5. As palavras-chave do capítulo sobre W.B. sāo: a democratizaçāo da cultura em respeito das massas, arte popular $\mathrm{e}$ o futuro da sociedade socialista. W.B. é um intelectual de educaçáo burguesa, que, apesar do stalinismo, tornouse marxista no sentido de utilizá-lo como uma metodologia para suas análises da obra de arte na sociedade industrial.

"W.B. Autocrítica e Dialética", in Folha de S. Paulo, "Folhetim", 9/12/1984, p. 11. Situa o pensador W.B. no marxismo deste século e confirma o otimismo histórico (messianismo) de W.B. em comparaçāo com Gramsci. As teses "Sobre o Conceito da História" seriam uma forte resposta contra o socialdemocratismo e o marxismo vulgar.

"W.B. O Marxismo da Melancolia". Rio de Janeiro, Campus, 1988. O livro mais biográfico que foi publicado no Brasil sobre W.B. comenta o que tem a ver o maxismo com a melancolia, os quais se unem a W.B. A melancolia significa, no sentido romântico, uma forma de despeito na auto-ironia. Nos momentos quase sem saida a melancolia torna-se rebelde. 
“W.B. um Revolucionário Conservador?", in OEstado de S. Paulo, "Suplemento Cultural", 22/9/1990, pp. 1-2. O autor questiona se W.B. era um "revolucionário conservador", como Habermas sugeriu, ou se não seria melhor afirmar que W.B. era mais radical do que todos os seus herdeiros da Escola de Frankfurt $e$ por isso ele provoca sempre.

"Idéias Políticas Continuam Atuais", in Folha de S. Paulo, "Mais!", 12/7/92, p. 7. Mantém a atualidade do pensamento de W.B. As idéias políticas dele continuam nos anos 90.

KOTHE, Flávio R. Para Ler Benjamin. Rio de Janeiro, Francisco Alves, 1976. Introdução à obra e aos conceitos de W.B. O objetivo do trabalho é servir de base para o conhecimento e interpretação da obra.

. Benjamin \& Adorno: Confrontos. São Paulo, Ática, 1978. A tese compara as obras de Adorno e W.B. com muito conhecimento da recepçāo da Alemanha nos anos $60 \mathrm{e} 70$. O livro versa sobre a sociologia da cultura, cita particularmente os textos menos conhecidos no Brasil, como por exemplo a Obra das Passagens.

."W.B. e Proust. Aura e Alegoria", in O Estado de S. Paulo, 20/10/1985, pp. 89. Sobre os conceitos de "aura" e"alegoria" nas obras de W.B. e Proust. A tarefa de W.B. era, com esses conceitos, desmistificar o mundo.

. "Introduçāo: Poesia e Proletariado. Ruinas e Rumos da Histónia", in W.B. Sociologia (ed. F. R. Kothe). Săo Paulo, Ática, 1985, pp. 7-27. Apresentaçāo dos textos centrais de W.B.em torno da Obra das Passagens. Caracteriza a obra dele em duas fases: idealista e materialista (marxista).

“W.B.", in Leia Livros n²86, dezembro de 85, p. 50. Resposta a Michael Loewy, que criticou a traduçāo e a introduçāo do livro W.B. Sociologia de Flávio R. Kothe.

LANDO, Vivien. "Experièncias", in Jornal do Brasil, 19/5/84, p. 2-B. Resenha do Livro Haxixe.

LIMA, Luiz Costa. “Auerbach, W.B., a Vida sob o Nazismo", in 34 Letras, n" 5-6, Rio de Janeiro, 1989, pp. 60-74. Entrevista com Karlheinz Barck(Berlim) a respeito do fundo das cartas de Auerbach a W.B., nas quais Auerbach queria indicá-lo para a USP.

LINS, Vera. “Gonzaga Duque: A Estratégia do Franco-Atirador”. Rio de Janeiro, Tempo Brasileiro, 1991. Olivrodedica-se a um autor brasileiro quase esquecido, Gonzaga Duque; utiliza-se do texto de W.B. "Parque Central" a fim de interpretar a obra daquele autor.

LOEWY, Michael. "O Teólogo do Marxismo", in Leia Livros $\mathrm{n}^{2} 85$, novembro de 85 , pp. 18-9. Resenha do livro W.B. Sociologia, textos escolhidos por Flávio R. Kothe.

. Redenção e Utopia. OJudaísmo L ibertário na Europa Central São Paulo, Companhia das Letras, 1989, pp. 85-109. O livro trata, particularmente, dos aspectos do messianismodentro do judaísmo na Europa. W.B. ocupa uma posiçāo central devido ao fato de ter juntado o messianismo com a política. Interpreta o texto "Sobre o Conceito de História".

Romantismo e Messianismo. Ensaios sobre Lukäcs e Benjamin. Sāo Paulo, Perspectiva/Edusp, 1990, pp. 147-74 e 189-213. O autor coloca em debate o judaísmo (messianismo) e o movimento político (marxista e romântico) da primeira 
etapa doséc. XXem ensaios inéditos sobre Lukácse W.B., desde 1969 até 1990.

"A Escola de Frankfurt e a Modernidade. W.B. e Habermas", in Novos Estudos $n^{2} 32$. Sáo Paulo, março de 1992, pp. 119-27. O ensaio explica o conceito de "modernidade" da Escola de Frankfurt e W.B. Critica o racionalismo de Habermas, o qual já foi criticado por Sergio P. Rouanet com os mesmos argumentos. O autor atualiza seu ponto de vista de 1985 em relação à obra de W.B.

MACHADO, Celuta Moreira Cesar. "Sobre a Lingua em Geral e a Língua dos Hornens: Indicaçôes para urna Possivel Leitura Semiótica", in Reflexōes Filosóficas (ed. Arley R. Moreno). Sāo Paulo, Editora da PUC-SP (EDUC), 1987, pp. 73-89. O ensaio trata a teoria da lingua de W.B. e argumenta contra a tendência da lingūística para o entendimento da linguagem como um instrumento arbitrário e funcional para finalidades de comunicaçāo.

MARTINS, Marilia. "Livraria Promove Palestras sobre W.B.", in Jornal do Brasil, 11/ 5/92, p. 5. Um artigo sobre duas palestras do estudioso benjaminiano Karlheinz Barck (Berlim) no Rio de Janeiro.

MATOS, Olgária Chain Feres. "Apresentação", in W.B. Haxixe. Sāo Paulo, Brasiliense, 1984, pp. 7 e segs. O livro Haxixe seria um bom exemplo para o pensamento fragmentário, descontínuo, incompleto de W.B.

. "Einbahnstrasse', a Rua de Mão Única de W.B.", in Folha de S. Paulo, 21/11/ 1987. p. A-32. Resenha do volume II das Obras Escolhidas de W.B. Interpretaçāo do texto Rua de Mão Única.

. "Marxismo e Psicanálise", in Folha de S. Paulo, "Folhetim", 11/3/1988, pp. 69. O artigo discute o conceito de "memória histórica", atinge entre outras "o flâneur" e "o sonho" na obra de W.B., cita a Obra das Passagens, A Infância Berlinense e Rua de Māo única. A autora afirma o aspecto fragmentário, descontínuo e inacabado na obra de W.B.

. "Konder Viaja com W.B. na Contramâo da Dialética", in Folha de S. Paulo, "Cademo Letras", 10/9/88, p. 2. Resenha do livro de Leandro Konder W.B.- O Marxismo da Melancolia.

- Os Arcanos do Inteiramente Outro. A Escola de Frankfurt. A Melancolia e a Revoluçāo. Sāo Paulo, Brasiliense, 1989, pp. 29-123. Olivro dedica-se à Escola de Frankfurt com parte central sobre W.B., cuja teoria barroca tornou-se fundamental para a "teoria crítica", segundo a autora.

. "Desejo de Evidência, Desejo de Vidência: W.B.", in ODesejo (ed. Funarte). Sāo Paulo, 1990, pp. 283-305. Este ensaio pretende mostrar como odesejo e a paixão se separam na filosofia moderna, desde Descartes. Afirma a necessidade de unir estes sentimentos com o objetivo de criar uma nova racionalidade, baseandose na obra de W.B.

. "W.B., o Principio Esperança", in Folha de S. Paulo, "Mais!", 12/7/92, p. 5. O ensaio dedica-se à filosofia da consciēncia. Questiona a separaçăo corpo e alma como foi feito na história moderna. W.B. é o representante dessa tentativa, e a filosofia dele, o instrumento para analisar e sintetizar a separaçāo - "o princípio esperança" é a palavra-chave.

MEDEIROS, Pedro. "W.B. O Choque do Cotidiano", in Jornal da Tarde, "Caderno de Sábado", 22/9/1990. Entrevista com o estudioso benjaminiano Norbert Bolz (Essen/Alemanha), participante do simpósio "7 perguntas a W.B." em São Paulo (1990), sobre o relacionamento entre W.B. e a Escola de Frankfurt. 
MENDONÇA, Antonio Sérgio. “Metáfora e Alegoria”, in Revista Brasileira de Lingua e Literatura $\mathrm{n}^{2} 2 / 1979$, Rio de Janeiro, pp. 13-8. Um estudo da metáfora e suas relaçōes categoriais, dedicado à definiçăo da obra de W.B., juntamente com o conceito de "alegoria". Engloba também uma semelhança no pensamento entre W.B. e Freud.

MERQUIOR, José Guilherme. Arte e Sociedade em Marcuse, Adorno e Benjamin. Ensaio Crítico sabre a Escola Neohegeliana de Frankfurt. Rio de Janeiro, Tempo Brasileiro, 1969. O primeiro livro no Brasil sobre W.B. trata a relação entre sociedade $e$ arte. É um ensaio crítico com os conceitos centrais da Escola de Frankfurt. O autor apresenta W.B. numa posiçâo contrária ao pensamento da "dialética negativa": "o declínio da aura" nos tempos modernos não eliminaria a esperança. Do ponto de vista do autor, W.B. foi o crítico literário mais famoso da primeira metade do século XX. Mostra quase toda a obra de W.B. e cita as palavras-chave com profundo conhecimento da filosofia ocidental.

. "A Caracterizaçáo do Moderno", in O Estado de S. Paulo, "Suplemento Cultural", 24/10/1976, pp. 4-5. Sobre o conceito de "pós-modernidade". Uma caracterizaçāo fundamentada nos conceitos de "declínio da aura" e "alegoria" de W.B. Trata também a relaçāo entre W.B. e Brecht e a obra de Kafka. O objetivo de W.B. era denunciar o mito e iluminar o processo histórico. O impulso antiromântico formula-se no triângulo vanguarda, mercado e sociedade. O protagonista do triângulo foi o poeta Baudelaire.

"Introduçāo: A Chave de Benjamin", in J.G.M., O Elixir do Apocalipse. Rio de Janeiro, Nova Fronteira, 1983, pp. LX-XIII. A introdução confirma o valor do método benjaminiano na crítica literária, no sentido de mostrar que texto literário ilumina os problemas atuais da cultura, mas no campoda filosofia da história, W.B. é, segundo Merquior, um profeta anti-revolucionário.

"Scholem: O Grau Zero da Mistica", in idem, pp. 33-8 (Folha de S. Paulo, "Folhetim", 30/5/82). Resenha do livrode G. Scholem que mostra obackground hebraico de W.B.

"O Elixir do Apocalipse", in idem, pp. 25-32 (Jornal do Brasil, 27/11/81, p. 7); nova ediçāo in J.G.M., Crítica. Ensaios sobre Arte e Literatura, Rio de Janeiro, Nova Fronteira, 1990. Resenha do livro de S. P. Rouanet Édipo e oAnjo, no qual Merquior faz uma distinçāo entre o crítico literário W.B., com quem se identifica, e o filósofo, o qual critica. Segundo o autor, para W.B. a modernidade era equivalente à repressâo, devido aos motivos existentes naquela época.

. "Entre a Técnica e o Apocalipse", in Folha de S. Paulo, "Folhetim", 1\%/9/1985, pp. 4 e segs. $O$ artigo é uma variaçāo da resenha do livro de S. P. Rouanet. Merquior critica os intelectuais que usam o texto de W.B. "Sobre o Conceito da História", de 1940, para a situação politica de hoje.

MURICY, Kátia. "Tradição e Barbárie em W.B.", in Revista Gávea n², Rio de Janeiro, junho/1986, Departamento de História da PUC-RJ, pp. 68-77. Uma interpretaçāo do livro Doutor Fausto de Thomas Mann com os conceitos benjaminianos das teses "Sobre o Conceito da História". Interpreta também essas teses dentro do contexto dos outros textos de W.B.

"O Autômatoe o Anäo", in Folha de S. Paulo, "Folhetim", 18/9/87,pp. B-4e segs. Sobre o conceito de "experiência" na sociedade industrial. $\mathrm{O}$ ato de relembrar seria o momento da liberaçāo do homem moderno do passado - contra o autômato sem memória.

"Viagem ao Planeta Benjamin", in Jornal do Brasil, 11/11/87. Resenha do vo- 
lume Il das Obras Escolhidas de W.B.

. "Golpes do Irracional", in Jornal do Brasil, 3/9/88, p. 3. Resenha do livro W.B. $O$ Marxismo da Melancolia de Leandro Konder. Também um breve ensaio sobre a recepção de W.B. no Brasil.

"W. B.: Política e Paixão", in Os Sentidos da Paixāo (ed. Funarte). São Paulo, Companhia das Letras, 1989, pp. 497-508. Em Baudelaire, como mostra a análise de W.B. sobre a obra do poeta, encontra-se a manifestação da fantasmagoria do Segundo Império, que é considerada em sua poesia como alegoria. A política seria a paixão que poderia livrar a humanidade do mito e realizar a felicidade.

"As Vésperas do Eclipse", in Jornal do Brasil, "ldéias Livros", 23/9/89. p. 3.

Resenha do livro de W.B. Diário de Moscou.

"Crítico da Cultura e História em W.B. e Nietzsche", in Boletim ANPOF, $\mathrm{n}^{\circ} 4$, janeiro-julho/1990, pp. 8-19. O ensaio confirma o aspecto interessante da ligaçâo do pensamento entre W.B. e Nietzsche, e acredita que o conceito da história e a crítica da cultura de W.B. ficam mais claros com o conhecimento de Nietzsche e a receppcáo dele por W.B.

NESTROVSKI, Arthur. "Tradutor Une Cacos da Lingua", in Folha de S. Paulo, "Mais!", $12 / 7 / 92$, p. 4 . Sobre a teoria da tradução, a filosofia e a critica literária em W.B. Interpreta, particularmente, o texto "A Tarefa do Tradutor".

PEIXOTO, Nelson Brissac. A Seduçāo da Barbárie. OMarxismona Modernidade. São Paulo, Brasiliense, 1982, pp.13499. Apresenta W.B. como um autor envolvido nos debates da República de Weimar. W.B. mostra tendências estéticas e político-econômicas ligadas ao socialismo e otimismo histórico. Fala sobre o conceito da "modernidade" e a figura do "flâneur".

PEREIRA, Paulo. "Atualidade de W.B.”, in Jornal de Letras, Rio de Janeiro, 1985, p. 5 b.

Sobre o conceito de "alegoria", que foi renovado por W.B., no trabalho de Lúcia Helena Totens e Tabus da Modernidade Brasileira. A modernidade deve a W.B. uma nova interpretação de alegoria e aura.

PEREIRA, Uilcan. "Apresentação da Ediçāo Brasileira”, in W.B., Reflexōes: a Criança, oBrinquedoe a Educaçâo. SãoPaulo, Summus, 1984.pp.9-12.O"renascimento do marxismo" exige mais textos sobre a prática. O livro faz uma coletânea dos textos de W.B. sobre infância e juventude.

RESENDE, André Luís. "W.B. Conta Delínos", in Folha de S. Paulo, "Folhetim", 25/ 5/1986, pp. 11 e segs. Crítica sobre a alusâo histórica, que foi, para W.B., um instrumento utilizado para dar vida a interpretaçōes filosóficas e literárias de profunda inquietaçāo argumentativa.

ROUANET, Sergio Paulo. Édipo e o Anjo. Itinerários Freudianos em W.B. Rio de Janeiro, Tempo Brasileiro, 1981. Na metodologia da flânerie o autor aproximasedos caminhos freudianos em W.B. Opensamento prismático e aparentemente contraditório serve para um país como o Brasil. Trata da arte, da crítica de arte, da teoria da língua e da psicologia das massas.

"Introduçāo", in W.B., Origem do Drama BarrocoAlemão. Sāo Paulo, Brasiliense, 1984. Explicação do motivo e as circunstâncias do trabalho de W.B., que é hoje um livro básico no estudo do drama barroco alemāo, e naquela época foi recusado pela universidade. O tradutor e estudioso benjaminiano mostra em três 
etapas a teoria da consciència, a teoria do drama barroco e a teoria da alegoria, fases fundamentais para a filosofia benjaminiana - com as palavras-chave, as quais nāo têm nada a ver com o irracionalismo.

"As Passagens de Paris", in S. P. R., As Razôes do Iluminismo. Săo Paulo, Companhia das Letras, 1987, pp. 37-109. Ensaio devido à publicação alemã da Obra das Passagens. O autor mostra o inicio e o processo do trabalho inacabado e comenta os capítulos do livro. W.B. já apresentou este trabalho no ensaio "Paris, Capital do Século XIX".

"O Falso Irracionalista", in idem, pp. 110-5 (Folha de S. Paulo, "Folhetim", 1\% 9/1985, pp. 6 e segs.). Uma polêmica contra a tendência coloca W.B. na faixa do irracionalismo. $\mathrm{O}$ autor mostra que o fundamento filosófico de W.B. é iluminista - a tarefa dele é despertar e iluminar a história dos seres humanos.

. "As Galerias do Sonho", in idem, pp. 116-23 (O Estado de S. Paulo, 10/11/85).

O artigo trata novamente os itinerários freudianos na obra de W.B., os quais năo foram, até o momento, atingidos na literatura secundária. Trata o sonho, a mímesis e confirma que o sonho para W.B. não se associa ao mito, mas à razão - no momento de despertar do sonho coletivo da história (miséria).

. "Porque o Modemo Envelhece", in Folha de S. Paulo, Mais!", 12/7/92, p. 6.

Trecho da palestra de S. P. R. durante o Simpósio sobre W.B. no Instituto Goethe, 1990. Análise da concepçāo de "modernidade" em M. Weber e W.B. A ambigüidade entre a tecnologia e o desenvolvimento humano, político e toda a sociedade.

SANTOS, Hamilton dos. "Benjamin, entre a Cabala e o Racional", in $O$ Estado de $S$. Paulo, 9/2/1989, p. 12. Resenha do livro W.B.- a História de uma Amizade, de Gershom Scholem.

SANTOS, Luis Sérgio. "Amor e Paixão em W.B.", in W.B., Curso de Comunicaçăo Social na Universidade Federal do Ceará, novembro/1990, p. 5. Comenta sobre a vida e a obra de W.B., particularmente do método benjaminiano. Faz citaçöes e comentários dos livros de Rouanet e Konder.

SCHEURMANN, Ingrid. "Morte no Exilio-AFuga Malograda de W.B. para a Espanha: Uma Aproximaçāo", in Humboldt $\mathrm{n}^{2}$ 62, Inter Nationes, Bonn, 1991, pp. 66-71. Ensaio sobre a fuga de W.B. e os últimos dias em Port Bou.

SCHWARTZ, Gilson. "Apresentaçāo", in Folha de S. Paulo, "d", 3/9/89, p. 7. O professor de economia apresenta o texto "Panorama Imperial" do livro Rua de Mão Única sobre os anos 20 na Alemanha, com a finalidade de comparar com a situaçăo da alta inflaçāo no Brasil.

SCLIAR, Moacyr. "Três Anjos Tristes Inspiram Pensador", in Folha de S. Paulo, "Mais!", $12 / 7 / 92$, p. 7. Sobre a melancolia da esquerda em W.B. Abordagem da imagem dos “anjos" para W.B. e citaçōes dos livtos de Konder e Rouanet.

SELIGMANN-SILVA, Márcio. "A Teoria da Linguagem. Textura e Leitura do Tempo", in Projeka n² 2, Revista de Cultura Brasileira e Alemã. Sāo Paulo, Associaçāo Brasileira de Associaçōes de Professores de Alemāo, novembro/90, pp. 14-7. Interpretaçāo da filosofia da linguagem de W.B., tratando todos os textos dele sobre a língua.

.Ler oLivro do Mundo. W.B. -Romantismoe Crítica Poética. São Paulo, FFLCHUSP, 1991. Dissertaçăo de mestrado, mimeografado. A tese analisa a época do romantismo alemāo e a teoria da crítica literária, no contexto da recepção por 
W.B., na sua obra $O$ Conceito de Crútica de Arte no Romantismo Alemão.

SEVCENKO, Nicolau. "W.B., a Inteligência Radical”, in Folha de S. Paulo, 1/9/1985, p. 83. Resenha sobre os livros W.B. Sociologia de Flávio R. Kothe e volume I das Obras Escolhidas da Editora Brasiliense.

SPIELMANN, Ellen. "W.B., Professor da USP", in Jornal do Brasil, "Idéias", 22/4/ 1989, p. 3. O artigo fala sobre a tentativa de Auerbach indicar W.B. para um cargo na nova faculdade de Letras da USP.

VASCONCELOS, Ruy. “Aspectos da Estética W.B.”, in W.B., Curso de Comunicaçăo Social na Universidade Federal do Ceara, novembro/1990, p. 7. Trechos biográficos e comentários sobre as obras principais de W.B. Discute, particularmente, a questáo da estética em torno de Baudelaire, Proust, Kafka e Joyce.

ZA.I DAN FILHO, Michel. A Crise da Razāo Histórica. Campinas, Papirus, 1989, pp. 37-70. Oprimeiro livro no Brasil que trata - polemicamente - a recepçâode W.B. Apesar da incorporaçäo de W.B. no "novo irracionalismo-nova historiografia" o autor aprecia os conceitos centrais de W.B.: a "alegoria" e as "imagens dialéticas".

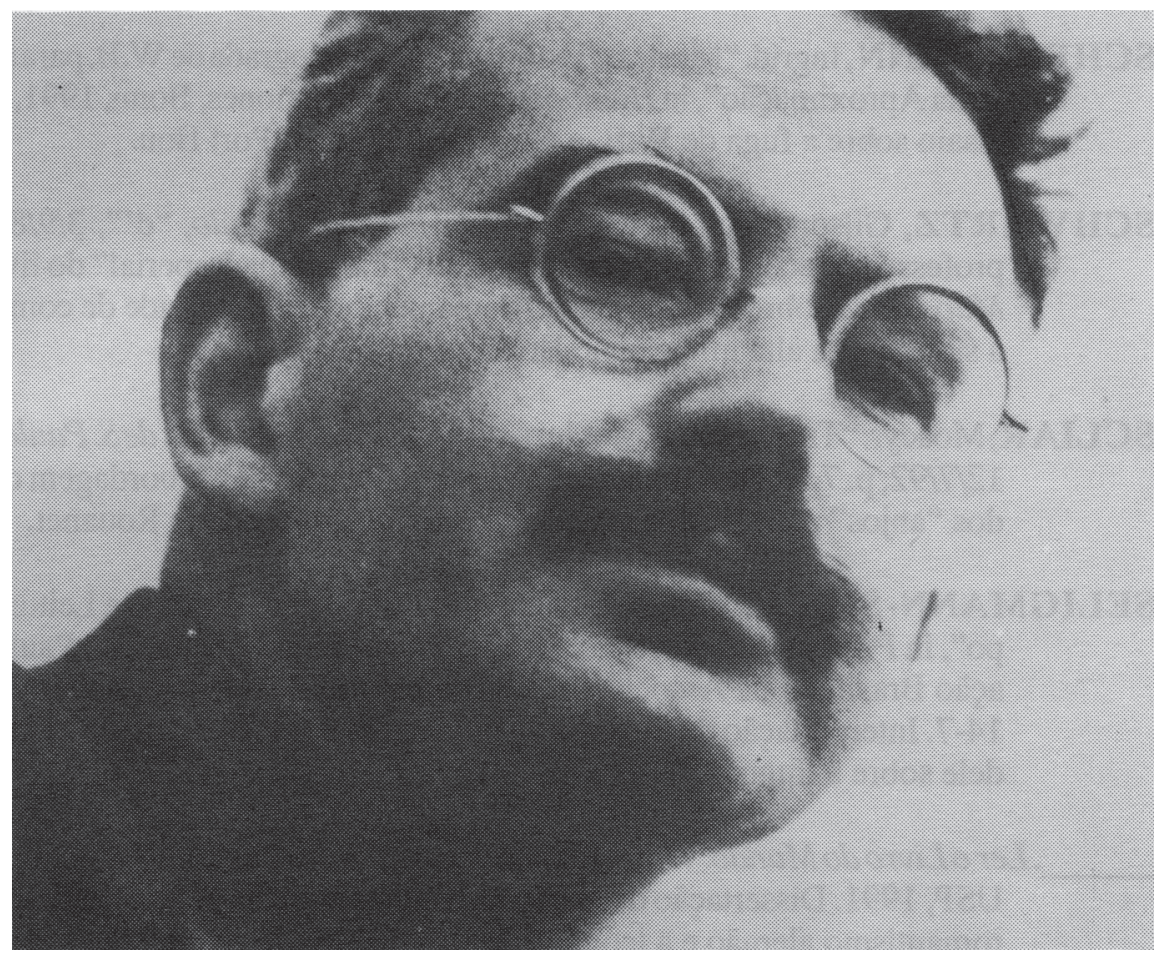


Na Revista USP ํ 16, na "Bibliografia Comentada das Obras sobre Walter Benjaminno Brasil", de Gunter KarlPressler, ficaram faltando, a partir de "DIAS, Carmen", várias outras referências, que publicamos agora, coma repetição desta primeira, que saiu incompleta.

DIAS, Carmen. "WilliBolle, na Trilha deW.B.", in OPovo, Fortaleza, 8/11/1990, p. B-6.Entrevistacomoestudioso benjaminiano, professor WilliBolle, quetrata oconceito de modernidade efala sobre osuicídio nos tempos modernos.

FIORILLO, Marília Pacheco. "Solitário, Suave, Trágico", in IstốE/Senhor , 18/4/1984,pp. 72-3. Resenha dos livros Reflexões: $A$ Criança, o Brinquedo e a Educação e Haxixe. " Não me Venham Falar em Síntese", in Folha de S. Paulo, "Folhetim", 9/12/ 1984 , p. 12. Entrevista com Sergio P. Rouanet sobre a tradução do livro Origem do Drama Barroco Alemão .

. "O Colecionador de Fracassos", in IstoE/Senhor , 11/10/1989, pp. 120-1. Resenha do livro Diário de Moscou.

GAGNEBIN, Jeanne-Marie. W.B. Os Cacos da História . São Paulo, Brasiliense, 1982. O livro versa sobre os momentos teológicos (não religiosos) na filosofia da história de W.B. Crítica sobre as diversas classificações utilizadas pelos intérpretes da obra deW.B. Eum alerta para que os mesmos se concentrem somente nos conceitos de W R

. "A propósito do Conceito de Crítica em W.B.", in Discurso $n^{\circ} 13$, revista do Departamento de Filosofia da FFLCH da USP, 1983. O ensaio fala sobre o desenvolvimento do conceito de "crítica" em W.B., discute a "obra aberta" (Umberto Eco), que já fora antecipada por W.B., e questiona a dialética e falsa totalidade dela.

. "As Drogas de W.B.: Palavra como Vinho", in Leia Livros no69, junho/1984, p. 7. Resenhadolivro Haxixe.

"Origem da Alegoria, Alegoria da Origem", in Folhade S. Paulo, "Folhetim", 9/12/ 1984, pp. 8-10. Umaleitura de Origem doDramaBarroco Alemão .Em debate os conceitos deorigem, salvação, tradução e alegoria.
"W.B. ou a História Aberta.Prefácio", inW.B., Obras Escolhidas Vol.1. Magiae Técnica, Arte e Política. Ensaios sobre Literaturae História da Cultura .São Paulo, Brasiliense, 1985, pp.7-19. Abordagem do conceito de "experiência" nafilosofia, interpretando as teses "Sobre o Conceito de História" (1940) e otexto "A Obra de Arte na Época de sua Reprodutibilidade Técnica" (1935).

"Narrar e Curar", in Folha de $S$. Paulo, "Folhetim", 1\%/9/1985, p. 11. O artigo trata sobre o conceito de "experiência" e a força da narração para salvar o passado.

"Notas sobre as Noções de Origem e Original em W.B.", in 34 Letras, $n \div 5 / 6$, Rio de Janeiro, setembro de 89, pp. 285-96. Análise das palavras-chave "origem" e "original" na obra de W.B. no contexto da modernidade. Comparação e crítica entre os conceitos no original alemão e as traduções em português. Discute o trabalho de Haroldo de Campos.

"Baudelaire, W.B. e o Moderno", in Folhade S. Paulo, 7/10/1989, pp. G 4-6. Introduçãoà filosofia de W.B., fazendoumaabordagem histórica. Trata a modernidade e a interpretação de Baudelaire porW.B., no contexto da Obradas Passagens .

GARBER, Klaus. "W.B.", in O Estado de $S$. Paulo, "Cultura", 18/7/92, p. 1. O autor trata os textos Origem do Drama Barroco Alemão e Passagens de Paris (Obra das Passagens) (1927-40) para mostrar e explicar o método benjaminiano na busca da verdade filosófica, nos objetos e detalhes do cotidiano. Umabusca tanto na obra de juventude quanto na obra tardia deW.B. 